\title{
EXPECTATIONS, LEARNING, AND THE CHANGING RELATIONSHIP BETWEEN OIL PRICES AND THE MACROECONOMY
}

\author{
FABIO MILANI
}

University of CALifornia, Irvine

\begin{abstract}
This paper estimates a structural general equilibrium model to investigate the changing relationship between the oil price and macroeconomic variables. The oil price, through the role of oil in production and consumption, affects aggregate demand and supply in the model. The assumption of rational expectations is relaxed in favor of learning. Oil prices, therefore, affect the economy through an additional channel, i.e. through their effect on the formation of agents' beliefs.

The estimated learning dynamics indicates that economic agents' perceptions about the effects of oil prices on the economy have changed over time: oil prices were perceived to have large effects on output and inflation in the 1970s, but only milder effects after the mid-1980s. Since expectations play a large role in the determination of output and inflation, the effects of oil price increases on expectations can magnify the response of macroeconomic variables to oil price shocks. In the estimated model, in fact, the implied responses of output and inflation to oil price shocks were much more pronounced in the 1970s than in 2008. Therefore, through the time variation in the impact of oil prices on beliefs, the paper can successfully explain the observed weakening of the effects of oil price shocks on real activity and inflation.
\end{abstract}

Keywords: Oil Price, Inflation Expectations, Learning, Monetary Policy, Effect of Energy Shocks, Bayesian Estimation.

JEL classification: E31, E32, E52, E58, Q43.

Date: First version: July 31, 2008. Revised version: February 7, 2009.

I am grateful to the editor and two anonymous referees for helpful comments and suggestions. Address for correspondence: Department of Economics, 3151 Social Science Plaza, University of California, Irvine, CA 92697-5100. Phone: 949-824-4519. Fax: 949-824-2182. E-mail: fmilani@uci.edu. Homepage: http://www.socsci.uci.edu/ fmilani. 


\section{Introduction}

Large and protracted increases in the price of oil have been typically associated with sharp downturns in economic activity and with high inflation. As shown by Hamilton (1983), in fact, rising oil prices preceded almost all post-war U.S. recessions before 1981. The oil price shocks in 1973 and 1979, in particular, are widely believed to have have been a major cause of the stagflation in the 1970s.

Oil price increases of comparable magnitude have also been observed more recently: in the late 1990s, in the 2003-2006 period, and from 2007 to July 2008, when the crude oil price reached a peak of US\$ 147 a barrel, before plunging later in the year. Recent oil price increases, however, had only mild effects on real activity and on the core inflation rate.

The recent experience is, therefore, suggestive of important shifts that have occurred in the relationship between oil prices and the macroeconomy.

The main scope of this paper is to propose an interpretation for the changing effects of oil price fluctuations on the economy and on the inflation rate over time, which emphasizes the changing effect that oil prices have had on the formation of economic agents' expectations and the role of learning.

The paper employs a simple structural model, which is based on Blanchard and Galí (2007), and which captures the interaction between the oil price and macroeconomic variables. Oil is a factor in production and oil (or energy) goods are part of the households' desired consumption basket. Current and expected fluctuations in the real oil price, therefore, affect both the aggregate demand and supply relations in the economy.

This paper relaxes the strong informational assumptions required by rational expectations and it assumes that economic agents form expectations from their perceived (although still near-rational) laws of motion of the economy, but without knowing the true values of the model coefficients. For example, they lack knowledge about the size of the effect of oil price changes on the economy (which would be common knowledge under rational expectations). Economic agents, therefore, 
attempt to learn those coefficients over time using historical data. ${ }^{1}$ Relaxing the assumption of fully-rational expectations seems sensible in modeling the relationship between macroeconomic variables and oil prices. Kyrtsou and Labys (2006) and Kyrtsou (2008), in fact, uncover a complex bidirectional relationship between inflation and commodity prices, in particular crude oil prices: their finding creates a difficulty for models that rely on the assumption of rational expectations.

In the model, a positive oil price shock can lead to a recession and to an increase in inflation through two channels. First, oil prices affect aggregate demand and supply with an effect whose size depends on the degree of price and wage rigidity and on the share of oil in the economy. But there is a second effect that operates through the formation of beliefs. When oil prices are perceived by economic agents, in real time, to have a large effect on the economy, higher oil prices lead to substantial downward revisions in output expectations and upward revisions in inflation expectations. Since expectations have a large impact on the current realizations of the variables in the model, the effect of the initial oil price shock is magnified (that is, expectations can become to some extent self-fulfilling). When expectations, instead, are less responsive (possibly because of a more credible monetary policy regime), the effects of oil price shocks on the economy are likely to be smaller.

The model is estimated using likelihood-based Bayesian methods. The initial beliefs regarding the effect of oil prices on output, inflation, and monetary policy choices, which are used to initialize the learning process, are jointly estimated with the rest of the model parameters. Agents then try to learn the coefficients through constant-gain learning, by updating their estimates based on the most recent forecast errors.

1.1. Results. The estimated evolution of beliefs shows that agents started off in the sample believing that oil prices had a large impact on output and inflation. The negative effects on output were perceived to be very large during all the 1970s.

\footnotetext{
${ }^{1}$ Examples of the application of similar models with learning in macroeconomics are presented in Sargent (1993, 1999) and Evans and Honkapohja (2001).
} 
Agents, however, started to update their beliefs in the middle 1980s, when the incoming data led them to perceive that oil prices had a smaller effect on the economy. The inferred learning process also reveals that the perceived inflationary effect of oil price increases has constantly fallen over the sample and it has become very small by 2008 .

The main contribution of the paper lies in showing that through the estimated time variation in the effects of oil prices on expectations, the model can successfully account for the changing relation between the oil price and the macroeconomy that has been observed. The impulse responses (time-varying in the model as a result of learning) show that oil price shocks had much larger effects on output and inflation in the 1970s than in 2008. The larger effects are not due to different monetary policies (which are shown to account for at most $20 \%$ of the total effect of oil price shocks), but mostly to the evolving expectations effect. The variance decomposition similarly indicates that the role of oil shocks as a source of economic fluctuations has weakened.

1.2. Relation to the Literature. The paper aims to contribute to the literature that studies the effects of oil price shocks on macroeconomic fluctuations (e.g., Bruno and Sachs, 1985, Hamilton, 1983, 1996, Bernanke et al., 1997) and, in particular, to the papers that illustrate how these effects have changed and become milder over time (e.g., Hooker, 1996, 2002, Blanchard and Galí, 2007, De Gregorio et al., 2007, Herrera and Pesavento, 2009). Among those, Blanchard and Galí (2007) propose shifts in the degree of real wage rigidity, in monetary policy, as well as a decline in the share of oil in the economy, as potential factors that may have played a role in attenuating the effects of oil shocks. These factors are all considered in the current paper, but they turn out to be less important than changes in expectations. The paper, therefore, offers a novel explanation that can account for the observed time variation in the effects of oil shocks.

The paper also adds to the debate on whether the recessionary effects of oil price increases are in reality mostly due to the contractionary monetary policies that are 
implemented in their response (Bernanke et al., 1997, Leduc and Sill, 2004): the findings here indicate that endogenous monetary policy responses can explain only a small part of the effects of oil price shocks. While these issues have been often analyzed in the context of atheoretical models, the choice of relying on an estimated general equilibrium framework is in line with other recent studies (e.g., Nakov and Pescatori, 2008).

The paper is finally related to the countless empirical studies that use the New Keynesian model (e.g., Lubik and Schorfheide, 2004, Giannoni and Woodford, 2005, Rabanal and Rubio-Ramírez, 2005, Smets and Wouters, 2007), as it shows the role of a variable, the real oil price, that is typically omitted from their analyses, and to the empirical studies that emphasize the importance of relaxing rational expectations and introducing learning to explain several features of macroeconomic data (e.g., Milani, 2006, 2007, 2008a,b, Adam, 2005, Orphanides and Williams, 2005). In this case, the paper highlights the role of learning in helping to explain the changing transmission of oil price shocks.

\section{MODEL}

This section presents a simple model, which is based on Blanchard and Galí (2007), ${ }^{2}$ and which can capture the interaction among the oil price, some of the main macroeconomic variables, and monetary policy choices. ${ }^{3}$

2.1. Households. The economy is populated by a continuum of identical households. Each household maximizes

$$
E_{0} \sum_{t=0}^{\infty} \beta^{t} U\left(\frac{C_{t}^{1+\sigma}}{1+\sigma}-\frac{N_{t}^{1+\varphi}}{1+\varphi}\right),
$$

where

$$
C_{t}=\Theta_{\chi} C_{e, t}^{\chi} C_{q, t}^{1-\chi}
$$

\footnotetext{
${ }^{2}$ The reader is referred to the original article for a detailed derivation of the main model equations.

${ }^{3}$ The model is presented under the conventional hypothesis of rational expectations. Later in the paper, this assumption will be relaxed in favor of learning. Honkapohja et al. (2003) discuss the (mild) conditions under which the derivation under rational expectations and learning lead to exactly the same log-linearized laws of motion.
} 
with $\Theta_{\chi} \equiv \chi^{-\chi}(1-\chi)^{-(1-\chi)}$. Therefore, households derive utility from total consumption $C_{t}$, which includes consumption of imported oil (or energy goods in general), denoted by $C_{e, t}$, and of a Dixit-Stiglitz index of differentiated domesticallyproduced goods $C_{q, t} \equiv\left(\int_{0}^{1} C_{q, t}(i)^{1-\frac{1}{\epsilon}} d i\right)^{\frac{\epsilon}{\epsilon-1}}$, and disutility from the hours of labor $N_{t}$ they supply to firms. The coefficient $0<\beta<1$ denotes the household's discount factor, $\sigma>0$ is the inverse of the intertemporal elasticity of substitution of consumption, $\varphi>0$ is the inverse of the Frisch elasticity of labor supply, $0<\chi<1$ denotes the share of oil in consumption, and $\epsilon$ denotes the elasticity of substitution among differentiated consumption goods.

Households maximize (2.1) subject to a sequence of period budget constraints

$$
P_{q, t} C_{q, t}+P_{e, t} C_{e, t}+B_{t}=W_{t} N_{t}+\left(1+i_{t-1}\right) B_{t-1}+\Pi_{t},
$$

where $P_{q, t} \equiv\left(\int_{0}^{1} P_{q, t}(i)^{1-\epsilon} d i\right)^{\frac{1}{1-\epsilon}}$ denotes the price index for domestic goods, $P_{e, t}$ denotes the price of oil (expressed in domestic currency), $i_{t}$ denotes the nominal interest rate, $B_{t}$ denotes bond holdings, $W_{t}$ denotes the nominal wage, and $\Pi_{t}$ denotes the share of profits received from monopolistically-competitive firms, to which households also supply labor.

2.2. Firms. There exists a continuum of firms in the economy, which operate under monopolistic competition and have sticky prices. Each firm produces the differentiated good $i$ (with $i \in[0,1]$ ) using the production function

$$
Q_{t}(i)=A_{t} E_{t}(i)^{\alpha_{e}} N_{t}(i)^{\alpha_{n}}
$$

with $\alpha_{e}+\alpha_{n} \leq 1$, where $\alpha_{e}$ and $\alpha_{n}$ denote the shares of oil and labor in production, and where $A_{t}$ denotes the state of technology (common across firms). ${ }^{4}$

Firms set prices à la Calvo: only a fraction $0<1-\theta<1$ of firms can change their price in a given period (the remaining firms keep their prices fixed). Firms face a common demand curve $Q_{t}(i)=Q_{t}\left(\frac{P_{t}(i)}{P_{i, t}}\right)^{-\epsilon}$ for their product, where $Q_{t} \equiv$

\footnotetext{
${ }^{4} \mathrm{~A}$ more complicated alternative would be to assume that capital also enters the production function and that the degree of capital utilization varies endogenously depending upon energy usage, as modeled in Finn (2000). Here, the paper abstracts from capital (which can be thought as fixed). Adding capital and variable capacity utilization would complicate the learning problem, especially if one wants to consider near-rational expectations, by assuming that agents use all the available regressors in their learning rule.
} 
$\left(\int_{0}^{1} Q_{t}(i)^{1-\frac{1}{\epsilon}} d i\right)^{\frac{\epsilon}{\epsilon-1}}$ denotes aggregate gross output. Each firm, therefore, faces the same decision problem and, if allowed to re-optimize, sets the common optimal price $P_{t}^{*}$ to maximize the expected present discounted value of future profits (subject to the demand curve constraint):

$$
\sum_{\tau=0}^{\infty} \theta^{\tau} E_{t}\left\{F_{t, T+\tau}\left(P_{t}^{*} Q_{t+\tau \mid t}-\Psi\left(Q_{t+\tau \mid t}\right)\right)\right\},
$$

where $F_{t, t+\tau} \equiv \beta^{\tau}\left(C_{t+\tau} / C_{t}\right)^{-\sigma}\left(P_{t} / P_{t+\tau}\right)$ denotes the stochastic discount factor, $\Psi(\cdot)$ is the cost function, and $\theta^{\tau}$ is used to discount for the probability that prices can remain fixed for the next $\tau$ periods.

Under balanced trade, in equilibrium the conditions $B_{t}=0$ and $P_{c, t} C_{t}=$ $P_{q, t} Q_{t}+P_{e, t} E_{t}$, where $P_{c, t}$ is the price of the consumption basket, hold. Value added (or real GDP), denoted by $Y_{t}$, is given by $P_{y, t} Y_{t}=P_{q, t} Q_{t}+P_{e, t} E_{t}$, where $P_{y, t}$ is the value added deflator. Using the expressions for consumption and value added deflators, i.e. $P_{c, t}=P_{q, t}^{1-\chi_{t}} P_{e, t}^{\chi_{t}}$ and $P_{y, t}=P_{q, t}\left(\frac{P_{e, t}}{P_{q, t}}\right)^{-\alpha_{e, t} /\left(1-\alpha_{e, t}\right)}$, the relation between value added and consumption becomes $Y_{t}=C_{t}\left(\frac{P_{e, t}}{P_{q, t}}\right)^{\left(\chi_{t}+\frac{\alpha_{e, t}}{1-\alpha_{e, t}}\right)}$.

2.3. Economy's Aggregate Dynamics. Log-linearization of the model's firstorder conditions around a zero-inflation steady state leads to the following equations, which summarize the aggregate dynamics of the economy:

$$
\begin{aligned}
y_{t} & =\widehat{E}_{t-1}\left[y_{t+1}-\frac{1}{\sigma}\left(i_{t}-\pi_{t+1}\right)-\frac{\alpha_{e, t}}{1-\alpha_{e, t}}\left(o p_{t+1}-o p_{t}\right)\right]+\zeta_{t} \\
\pi_{t} & =\widehat{E}_{t-1}\left[\beta \pi_{t+1}+\kappa_{t} y_{t}+\lambda_{p, t} \Gamma_{e, t} o p_{t}\right]+u_{t} \\
i_{t} & =\rho_{t} i_{t-1}+\left(1-\rho_{t}\right)\left[\chi_{\pi, t} \pi_{t}+\chi_{y, t} y_{t}+\chi_{o, t} o p_{t}\right]+\varepsilon_{t}
\end{aligned}
$$

where $y_{t}$ denotes log real GDP (or value added), $\pi_{t}$ denotes domestic inflation, $i_{t}$ denotes the nominal interest rate, and $o p_{t}$ denotes the real oil price. Oil price shocks are assumed to be predetermined

$$
o p_{t}=\rho_{o p} o p_{t-1}+\delta_{o p, r}\left(i_{t-1}-\pi_{t-1}\right)+\delta_{o p, y} y_{t-1}+v_{t} .
$$

Equation (2.6) is the log-linearized Euler equation that arises from households' optimal choice of consumption. Output in period $t$ depends on expected output in $t+1$, on the expected real interest rate, and on real oil prices in $t$ and $t+1$. 
Expectations of future oil price increases have recessionary effects on current output, whose magnitude depends on the share of oil in production $\alpha_{e, t}$. The term $\zeta_{t}$ denotes an aggregate demand shock, which can be obtained endogenously as a combination of taste, technology, or government spending shocks. ${ }^{5}$

Notice that I have assumed predetermined expenditure and pricing decisions, following Woodford (2003). This is why, in the model, expectations about future variables are formed at $t-1$ rather than at $t$. Alternatively, one might interpret this assumption as requiring agents to form expectations about $t+1$ without observing current $t$ information. This assumption is usually employed to obtain more realistic delays in the effects of monetary policy and has the reasonable feature that expectations about monetary policy $\left(\widehat{E}_{t-1} i_{t}\right)$ matter for aggregate demand.

Equation (2.7) is a New Keynesian Phillips curve, in which the inflation rate $\pi_{t}$ depends on expected inflation in $t+1$, on output, on the real oil price, and on a costpush shock $u_{t}$. The coefficients $\kappa_{t}, \lambda_{p, t}$, and $\Gamma_{e, t}$ are combinations of several structural parameters: $\kappa_{t} \equiv \lambda_{p, t} \Gamma_{n, t} \frac{1-\alpha_{e, t}}{\alpha_{n}}, \lambda_{p, t} \equiv\left(\frac{(1-\theta)(1-\beta \theta)}{\theta}\right)\left(\frac{\left(\alpha_{e, t}+\alpha_{n}\right)}{1+\left(1-\alpha_{e, t}-\alpha_{n}\right)(\epsilon-1)}\right)$, $\Gamma_{e, t} \equiv \frac{\gamma_{t}\left(\alpha_{e, t}+\left(1-\alpha_{e, t}\right) \chi_{t}\right)}{1-\left(1-\gamma_{t}\right)\left(\alpha_{e, t}-\left(1-\alpha_{e, t}\right) \eta_{t}\right)}$, with $\Gamma_{n, t} \equiv \frac{\gamma_{t}\left(1-\alpha_{e, t}-\alpha_{n}\right)+\left(1-\gamma_{t}\right)\left(1-\alpha_{e, t}\right)(1+\phi)}{1-\left(1-\gamma_{t}\right)\left(\alpha_{e, t}-\left(1-\alpha_{e, t}\right) \eta_{t}\right)}$, and $\eta_{t} \equiv \frac{\alpha_{e, t}}{\mu-\alpha_{e, t}}$, where $\mu \equiv \epsilon /(\epsilon-1)$ denotes the steady-state markup of prices over marginal costs and $\gamma_{t}$ denotes the degree of real wage rigidity in the labor market. In the model, in fact, under flexible labor markets, the real wage would equal the MRS at all times, that is $w_{t}-p_{t}=c_{t}+\varphi n_{t}$. Labor rigidities are introduced, here, in a parsimonious way by modifying the previous equation as $w_{t}-p_{t}=\left(1-\gamma_{t}\right)\left(c_{t}+\varphi n_{t}\right)$, where $\gamma_{t}$ indicates the degree of real wage rigidities. This equation allows the real wage to not fully adjust every period to its level implied by perfectly competitive markets. It can be seen from the expression for $\Gamma_{n, t}$ that the higher the degree of real wage rigidity $\gamma_{t}$, or the higher the shares of oil in production or consumption (which increase the term $\left.\left[\alpha_{e, t}+\left(1-\alpha_{e, t}\right) \chi_{t}\right)\right]$, the higher the effect of oil prices on

\footnotetext{
${ }^{5}$ The paper does not attempt to offer an entirely structural interpretation of this shock, as it is not the main focus of the analysis. The paper will be mostly interested, instead, in studying the effects of the oil price shock.
} 
inflation. When the labor market is flexible, i.e. $\gamma_{t}=0$, inflation is not directly affected by oil price changes $\left(\Gamma_{e, t}=0\right)$.

The model is closed by specifying a monetary policy rule. Equation (2.8) is a Taylor rule, which is typically found to provide a good approximation of U.S. monetary policy by the Federal Reserve. The central bank in the model is assumed to react to inflation, output, and to the real oil price; $\chi_{\pi, t}, \chi_{y, t}$, and $\chi_{o p, t}$ represent the feedback coefficients, while $\rho_{t}$ captures the degree of interest-rate smoothing. The response to oil prices is included to verify whether a different monetary policy behavior over time with respect to oil is indeed an important element to explain the data (as argued, for example, by Bernanke et al., 1997).

Oil prices are usually taken as exogenous when studying their effects on the economy. This assumption is increasingly challenged (see, for evidence against exogeneity, Kilian, 2008). This paper does not try to model the oil demand and supply side; oil price shocks, however, are not considered as fully exogenous, but merely as predetermined with respect to the remaining endogenous variables in the system, $y_{t}, \pi_{t}$, and $i_{t}$. Kilian (2009) discusses how, while exogeneity may be an unrealistic assumption in oil-price modeling, the less restrictive hypothesis that oil price shocks are predetermined is more likely to be satisfied in practice (as it simply requires that oil prices do not respond to U.S. output and real interest rates within the quarter). Equation (2.9), therefore, allows the real price of oil to depend on past output and real interest rates ( $\delta_{o p, y}$ and $\delta_{o p, i}$ denote the corresponding elasticities); $\rho_{o p}$ accounts for the persistence in oil prices.

The disturbances $\zeta_{t}, u_{t}$, and $v_{t}$ are assumed to evolve as $\operatorname{AR}(1)$ processes, i.e., $\zeta_{t}=\rho_{\zeta} \zeta_{t-1}+\sigma_{\zeta, t} \nu_{\zeta, t}, u_{t}=\rho_{u} u_{t-1}+\sigma_{u, t} \nu_{u, t}$, and $v_{t}=\rho_{v} v_{t-1}+\sigma_{v, t} \nu_{v, t}$, while $\varepsilon_{t}$ is assumed to be white noise with standard deviation $\sigma_{\varepsilon, t}$.

The sample in the estimation will cover the period between 1960:q1 and 2008:q1. The assumption that all parameters have been stable over the sample may be unrealistic. In particular, there is extensive evidence that monetary policy has become more aggressive toward inflation after Volcker's appointment as Chairman 
of the Federal Reserve in 1979 (e.g., Clarida et al., 2000, Lubik and Schorfheide, 2004), and that the shocks that have hit the economy were drawn from distributions with smaller variance after around the same period (e.g., Sims and Zha, 2006). The estimation allows several coefficients to depend on time $t$. Most of them are allowed to switch in value around $1979:^{6}$

$$
\Delta_{t}= \begin{cases}\Delta_{\text {pre }-79} & t \leq 1979: 03 \\ \Delta_{\text {post-79 }} & t \geq 1979: 04\end{cases}
$$

where $\Delta_{t}$ collects each coefficient that is allowed to vary in this way, i.e. $\Delta_{t}=$ $\left(\gamma_{t}, \chi_{p i, t}, \chi_{y, t}, \chi_{o p, t}, \sigma_{\zeta, t}, \sigma_{u, t}, \sigma_{\varepsilon, t}, \sigma_{v, t}\right)^{\prime}$. The coefficients denoting oil shares $\chi_{t}$ and $\alpha_{e, t}$, instead, vary continuously at each $t$ over the sample.

In the model, $\widehat{E}$ denotes subjective expectations, which may differ from the mathematical expectations operator $E$ conditioned on all the available information. The next section describes the expectations formation mechanism in more detail.

2.4. Learning and the Formation of Expectations. In the model, agents' expectations about future economic conditions play a central role: consumers and firms need to form forecasts about future aggregate output, inflation, and monetary policies, to solve their consumption and price-setting decisions; the dynamics of current output and inflation, therefore, are crucially affected by the state of expectations.

Evans and Honkapohja (2008) discuss the strong informational assumptions required by the rational expectations hypothesis that is conventionally employed in macroeconomic analysis and review the literature that considers departures from rational expectations by assuming learning. This paper follows a similar approach in modeling the expectations formation of the agents.

The paper relaxes the assumption of fully-rational expectations and it assumes that agents have near-rational expectations and that they try to learn the parameters of the economy over time.

\footnotetext{
${ }^{6}$ Having a model with fixed coefficients doesn't change the main results of the paper regarding the effect of oil shocks; incorporating the switches in the coefficients, particularly in the variances of the shocks, however, considerably improves the model fit.
} 
Agents adopt a perceived (linear) model of the economy

$$
\left[\begin{array}{c}
y_{t} \\
\pi_{t} \\
i_{t} \\
o p_{t}
\end{array}\right]=\left(\begin{array}{c}
\phi_{t}^{y, 0} \\
\phi_{t}^{\pi, 0} \\
\phi_{t}^{i, 0} \\
\phi_{t}^{o p, 0}
\end{array}\right)+\left(\begin{array}{cccc}
\phi_{t}^{y, y} & \phi_{t}^{y, \pi} & \phi_{t}^{y, i} & \phi_{t}^{y, o p} \\
\phi_{t}^{\pi, y} & \phi_{t}^{\pi, \pi} & \phi_{t}^{\pi, i} & \phi_{t}^{\pi, o p} \\
\phi_{t}^{i, y} & \phi_{t}^{i, \pi} & \phi_{t}^{i, i} & \phi_{t}^{i, o p} \\
\phi_{t}^{o p, y} & \phi_{t}^{o p, \pi} & \phi_{t}^{o p, i} & \phi_{t}^{o p, o p}
\end{array}\right)\left[\begin{array}{c}
y_{t-1} \\
\pi_{t-1} \\
i_{t-1} \\
o p_{t-1}
\end{array}\right]+e_{t},
$$

where $e_{t}$ is a vector of residuals. These expectations are near-rational since agents use the same observable regressors that would appear in the solution of the model under rational expectations; ${ }^{7}$ they are not given knowledge, instead, of the unobservable shocks. Agents also lack knowledge about the parameters of the system. They use historical data to learn about those parameters over time (that is, agents are assumed to behave similarly to econometricians that revise their estimates as the sample expands). ${ }^{8}$

Each period, economic subjects update their estimates of all the $\phi_{t}$ 's according to the constant-gain learning formula

$$
\begin{aligned}
\widehat{\mathbf{\Phi}}_{t} & =\widehat{\boldsymbol{\Phi}}_{t-1}+\overline{\mathbf{g}} R_{t}^{-1} X_{t}\left[Z_{t}-X_{t}^{\prime} \widehat{\boldsymbol{\Phi}}_{t-1}\right] \\
R_{t} & =R_{t-1}+\mathbf{g}\left[X_{t} X_{t}^{\prime}-R_{t-1}\right]
\end{aligned}
$$

where (2.11) describes the updating of the learning rule coefficients in (2.10), which are collected in $\widehat{\boldsymbol{\Phi}}_{t},(2.12)$ characterizes the updating of the precision matrix (the inverse of the covariance matrix) $R_{t}$ of the stacked regressors $X_{t} \equiv$ $\left\{1, y_{t-1}, \pi_{t-1}, i_{t-1}, o p_{t-1}\right\}$, and $Z_{t} \equiv\left[y_{t}, \pi_{t}, i_{t}, o p_{t}\right]^{\prime}$ collects the endogenous variables. $\mathbf{g}$ denotes the constant gain coefficient, which indicates the weight at which agents discount old information in deriving updated estimates. Constant-gain learning is typically thought to be desirable and to perform well in situations in which the agents may be concerned about future structural breaks in the parameters at

\footnotetext{
${ }^{7}$ The use of filtered series, instead of the original levels of the variables, although common in DSGE analyses, may be problematic as the expectational equations may not hold exactly as in (2.10). This issue, which is discussed in more length in Fukac and Pagan (2006), is, however, not tackled in the current paper.

${ }^{8}$ Of course, this does not mean that agents should actually behave in such a way, but it is meant as an approximation that allows to mimic features of agents' real world adaptive behavior.
} 
unknown dates. Since the presented model contains several coefficients that may change over time, allowing agents to learn with a constant gain is an obvious choice.

To form expectations for $t+1$, economic agents, therefore, use (2.10) and the most recent parameter estimates in (2.11) and (2.12) to obtain

$$
\begin{aligned}
& \widehat{E}_{t-1}\left[\begin{array}{c}
y_{t+1} \\
\pi_{t+1} \\
i_{t+1} \\
o p_{t+1}
\end{array}\right]=\left(\begin{array}{c}
\phi_{t-1}^{y, 0} \\
\phi_{t-1}^{\pi, 0} \\
\phi_{t-1}^{i, 0} \\
\phi_{t-1}^{o p, 0}
\end{array}\right) {\left[I+\left(\begin{array}{cccc}
\phi_{t-1}^{y, y} & \phi_{t-1}^{y, \pi} & \phi_{t-1}^{y, i} & \phi_{t-1}^{y, o p} \\
\phi_{t-1}^{\pi, y} & \phi_{t-1}^{\pi, \pi} & \phi_{t-1}^{\pi, i} & \phi_{t-1}^{\pi, o p} \\
\phi_{t-1}^{i, y} & \phi_{t-1}^{i, \pi} & \phi_{t-1}^{i, i} & \phi_{t-1}^{i, o p} \\
\phi_{t-1}^{o p, y} & \phi_{t-1}^{o p, \pi} & \phi_{t-1}^{o p, i} & \phi_{t-1}^{o p, o p}
\end{array}\right)\right]+} \\
&+\left(\begin{array}{cccc}
\phi_{t-1}^{y, y} & \phi_{t-1}^{y, \pi} & \phi_{t-1}^{y, i} & \phi_{t-1}^{y, o p} \\
\phi_{t-1}^{\pi, y} & \phi_{t-1}^{\pi, \pi} & \phi_{t-1}^{\pi, i} & \phi_{t-1}^{\pi, o p} \\
\phi_{t-1}^{i, y} & \phi_{t-1}^{i, \pi} & \phi_{t-1}^{i, i} & \phi_{t-1}^{i, o p} \\
\phi_{t-1}^{o p, y} & \phi_{t-1}^{o p, \pi} & \phi_{t-1}^{o p, i} & \phi_{t-1}^{o p, o p}
\end{array}\right)^{2}\left[\begin{array}{c}
y_{t-1} \\
\pi_{t-1} \\
i_{t-1} \\
o p_{t-1}
\end{array}\right]
\end{aligned}
$$

where $I$ denotes the identity matrix. Expectations formed as in (2.13) from the agents' perceived law of motion (2.10) can be substituted into the aggregate laws of motion (2.6) to (2.9) to obtain the Actual Law of Motion of the economy: ${ }^{9}$

$$
\begin{aligned}
\xi_{t} & =A_{t}+F_{t} \xi_{t-1}+G_{t} \varpi_{t} \\
Z_{t} & =H \xi_{t}
\end{aligned}
$$

where $\xi_{t}=\left[y_{t}, \pi_{t}, i_{t}, o p_{t}, \zeta_{t}, u_{t}, v_{t}\right]^{\prime}$ is the vector of state variables (which includes the observable variables in $Z_{t}$ along with the unobservable shocks), $\varpi_{t}=\left[\varepsilon_{t}, \nu_{\zeta, t}, \nu_{u, t}, \nu_{v, t}\right]^{\prime}$ is a vector of exogenous innovations, and where $H$ is simply a $4 \times 7$ matrix of zeros and ones, which selects the observable variables from $\xi_{t}$ (i.e., the first four elements). The vectors and matrices of parameters $A, F$, and $G$, may depend on both the structural parameters of the economy and on the learning coefficients and they can vary over time as a result of changing structural coefficients, standard deviations of the shocks, and learning dynamics. The system in (2.14) is in state-space form and it is linear; moreover, the exogenous shocks $\varpi_{t}$ are assumed to be normallydistributed. Therefore, the likelihood of the system can be obtained through the Kalman filter at each iteration of the Metropolis-Hastings algorithm, which will be used to generate draws from the posterior distribution in the full-system Bayesian estimation.

\footnotetext{
${ }^{9}$ The system with learning becomes self-referential, as the learning process and the structure of the economy continuously affect each other.
} 
To estimate the model under learning, one needs to initialize the learning algorithm in (2.11)-(2.12), by choosing the initial beliefs $\Phi$ and $R$ at time $t=0$. The matrix $R_{t=0}$ is initialized using the first $t_{0}$ pre-sample (1951-1959) observations as $E\left[X_{t 0}^{\prime} X_{t 0}\right]$. The choice of $\Phi$ is also informed by pre-sample data: the initial beliefs are characterized by a low perceived persistence for inflation $\left(\phi_{t=0}^{\pi, \pi}=0\right)$, limited persistence for interest rates $\left(\phi_{t=0}^{i, i}=0.6\right)$, large persistence for output and oil prices $\left(\phi_{t=0}^{y, y}=\phi_{t=0}^{o p, o p}=0.9\right)$, and a relatively large sensitivity of inflation to output $\left(\phi_{t=0}^{\pi, y}=0.1\right)$ and of output to the real interest rate $\left(\phi_{t=0}^{y, i}=-0.5, \phi_{t=0}^{y, \pi}=0.5\right)$. In the empirical analysis, I will verify the sensitivity of the results to some alternative initializations.

As regards the initial beliefs that reflect the perceived effect of oil prices on output, inflation, and interest rates, instead of fixing them, I will let the data decide about their best-fitting values. Therefore, $\phi_{t=0}^{y, o p}, \phi_{t=0}^{\pi, o p}$, and $\phi_{t=0}^{i, o p}$ will be jointly estimated along with the other structural parameters in the model.

\section{Near-Rational Expectations Econometrics}

The model is estimated to fit the data on U.S. output, inflation, the nominal interest rate, and the real oil price. The estimation uses quarterly series for the 1960:q1-2008:q1 sample. Output is given by log Real GDP, which is detrended using the Hodrick-Prescott filter, inflation is defined as the quarterly change in the GDP Implicit Price Deflator, the nominal interest rate (the policy instrument in the model) is given by the Federal Funds Rate, and the real oil price is calculated as the log of the West Texas Intermediate spot oil price (Dollars per Barrel) times one hundred and deflated using the GDP Implicit Price Deflator. All data series have been downloaded from FRED ${ }^{\circledR}$, the Federal Reserve Economic Database, maintained by the Federal Reserve Bank of St. Louis. ${ }^{10}$

Some coefficients will be fixed in the estimation. The discount factor $\beta$ is fixed at 0.99, the inverse of the Frisch elasticity of labor supply $\varphi$ is fixed at 1 , the elasticity among differentiated products $\epsilon$ is assumed equal to 11 (which implies a steady-state

\footnotetext{
${ }^{10}$ The series IDs are GDPC96, GDPDEF, FEDFUNDS, and OILPRICE.
} 
mark-up of prices over marginal costs of 10\%), and the share of labor in production $\alpha_{n}$ is fixed at 0.7 . The constant-gain coefficient is assumed to equal 0.02 , which is close to the value estimated in Milani (2007) in a similar model and represents the benchmark value employed in most empirical analyses (e.g., Orphanides and Williams, 2005).

Two important parameters, which affect the impact of oil prices on output and inflation, are given by $\chi_{t}$, the share of oil in the consumption basket, and $\alpha_{e, t}$, the share of oil in production. ${ }^{11}$ To reflect the changing importance of oil in the U.S. economy, both shares are allowed to vary over time. The oil share in consumption, at each period $t$, is calculated as the Personal Consumption Expenditure in energy goods and services as a fraction of total consumption expenditures. The oil share in production is given at each $t$ by the series on the Relative Importance of Crude Oil in Industrial Production (which is already given as a percentage). All series necessary to calculate $\chi_{t}$ and $\alpha_{e, t}$ are obtained from the DRI-Global Insight database. ${ }^{12}$ The time-varying shares are displayed in Figure 1. It should be noticed that time variation in the energy shares in consumption and production in this paper simply reflects time variation in the corresponding preference and technology parameters. The paper takes them as given and does not try to explain their time series. The time variation in energy shares can be well approximated by assuming the presence of putty-clay capital in the model, as in Atkeson and Kehoe (1999) and Wei (2003).

The vector $\Theta$ collects the coefficients that need to be estimated

$$
\begin{array}{r}
\Theta=\left\{\sigma, \theta, \gamma_{t}, \rho_{t}, \chi_{\pi, t}, \chi_{y, t}, \chi_{o p, t}, \rho_{\zeta}, \rho_{u}, \rho_{v}, \sigma_{\zeta, t}, \sigma_{u, t}, \sigma_{v, t}, \sigma_{\varepsilon, t},\right. \\
\left.\delta_{o p, y}, \delta_{o p, r}, \rho_{o p}, \phi_{t=0}^{y, o p}, \phi_{t=0}^{\pi, o p}, \phi_{t=0}^{i, o p}\right\},
\end{array}
$$

and which include households' preference parameters, the degrees of price and wage rigidity, the monetary policy rule coefficients, the oil price equation coefficients,

\footnotetext{
${ }^{11}$ For example, the share of oil in production affects the sensitivity of output to oil prices in (2.6), given by $\frac{\alpha_{e, t}}{1-\alpha_{e, t}}$.

${ }^{12}$ The data relative to the oil shares in production are available from 1972:II (for the early part of the sample, therefore, the share is assigned its 1972 value), while those relative to the oil shares in consumption are available from 1960:I.
} 
along with the estimated initial beliefs, and the standard deviations and autoregressive terms for the shocks; several of these parameters will be allowed to differ in the pre- and post-1979 samples. In particular, a number of studies have argued that it is important in empirical analyses to allow for changes in policy and, even more importantly, in the variances of the shocks starting from the early 1980s (e.g., Clarida et al., 2000, Lubik and Schorfheide, 2004, Sims and Zha, 2006).

The model is estimated by likelihood-based Bayesian methods. ${ }^{13}$ The estimation techniques follow Milani (2007), who extends the approach described in An and Schorfheide (2007) to permit the estimation of DSGE models with near-rational expectations and learning by economic agents. I run 300,000 Metropolis-Hastings draws, discarding the first $25 \%$ as initial burn-in and thinning the chain, so that only one every hundred draws is retained to reduce the autocorrelation of the draws (longer chains led to essentially the same results).

3.1. Prior Distributions. Table 1 illustrates the choice of the prior distributions for the coefficients in $\Theta$. The intertemporal elasticity of substitution $\sigma$ has a Gamma prior distribution with mean 1 and standard deviation 0.5. The Calvo parameter $\theta$ has a Beta prior distribution with mean 0.7 and standard deviation 0.11 . For the real wage rigidity coefficients, I center the Beta prior distribution at 0.9 for the pre-1979 period and at 0.6 for the post-1979 period: these numbers indicate more rigid labor markets in the 1960s and 1970s than in the following decades and correspond to the values used by Blanchard and Galí (2007).

For the monetary policy rule, I assume Normal distributions with mean 1.5 and standard deviation 0.25 for the inflation feedback and with mean 0.25 and standard deviation 0.125 for the output and real oil price feedback coefficients. All the autoregressive coefficients are assumed to follow Beta distributions (to guarantee that they remain in the $[0,1]$ range) and the standard deviations of the shocks follow inverse Gamma distributions.

\footnotetext{
${ }^{13}$ For a discussion of the advantages of Bayesian versus Classical estimation of DSGE models, see for example Fernandez-Villaverde and Rubio-Ramírez (2004).
} 
The coefficients that describe agents' initial beliefs at the beginning of the sample will also be estimated. I assume a Gamma prior distribution with mean 1 and standard deviation 0.7 for $-\phi_{t=0}^{y, o p}$, the perceived effect of oil prices on output, with mean 1 and standard deviation 0.58 for $\phi_{t=0}^{\pi, o p}$, the perceived effect of oil prices on inflation, and with mean 0.25 and standard deviation 0.18 for $\phi_{t=0}^{i, o p}$, the perceived response of monetary policy to oil prices.

\section{EMPIRICAL Results:}

\section{LEARning AND the DeClining Impact of EnERgy Shocks}

4.1. Posterior Estimates. The mean posterior estimates for the coefficients are reported in Table 1, together with the $95 \%$ highest posterior density intervals.

The posterior mean for the intertemporal elasticity of substitution coefficient $\sigma$ equals 3.098, while the Calvo price stickiness parameter $\theta$ has mean 0.764, which indicates that firms update their prices on average every four quarters. While this estimate implies more price rigidity than found by Bils and Klenow (2004), from micro data, and by Altig et al. (2005), by assuming firm-specific capital, the value is common in estimated DSGE models and it is consistent with the more recent micro evidence on price setting provided by Nakamura and Steinsson (2008), who find, based on CPI micro data, that the median duration of consumer prices is between 8 and 11 months. The estimated monetary policy coefficients indicate a switch in the aggressiveness toward inflation in 1979: the posterior mean estimate for $\chi_{\pi, t}$ increases from 1.26 to 1.52 . There is a small reduction in the reaction to output, while the estimates do not provide evidence in favor of significant differences in the policy reaction to oil prices across samples. There is evidence, instead, of changes in the standard deviations of the structural shocks, in particular about the demand shock $\zeta_{t}$ : the posterior mean falls from 0.88 to 0.61 .

Regarding the degrees of real wage rigidity, the data do not seem informative on their value. Their posterior distributions substantially reflect the priors, indicating that the likelihood is flat in those parameters. ${ }^{14}$

\footnotetext{
${ }^{14}$ As well known, and discussed in Poirier (1998), non-identification of some of the parameters does not pose particular problems for the estimation under the Bayesian approach. For the
} 
Turning to the oil price equation, it seems that there are no strong effects of output and interest rates on the oil price, at least if estimated with a constant coefficient over the whole sample, as in this case.

Finally, the initial beliefs of the agents regarding the impact of oil prices, which are used to initialize the learning process in (2.11), are also estimated from the data, rather than fixed a priori. The posterior mean estimate for the perceived effect of the oil price on output in the early part of the sample equals -1.01 , on inflation it equals 0.45 , and the perceived response of monetary policy to oil prices equals 0.26 .

4.2. The Time-Varying Effects of Energy Shocks. The price of oil affects the economy through its effect on aggregate demand and supply, as apparent from equations (2.6) and (2.7); the magnitude of the effect depends on the shares of oil in production and consumption. Changes in the oil shares, however, cannot by themselves explain the falling impact that oil prices seem to have on the economy.

But, in the model, the impact of oil price fluctuations can be magnified and can vary over time through a second effect. Oil prices, in fact, also affect economic agents' expectations about future economic conditions, inflation, and future monetary policies, through their effect on (2.10).

The estimated coefficients describing the initial beliefs of agents are reported in Table 1. As new data become available over the sample, agents revise their estimates in the direction of the most recent forecast errors and they attempt to learn about the (reduced-form) coefficients of the economy. The estimated evolution of all agents' beliefs is shown in Figure 2. The main beliefs of interest are those related to the effect of oil prices on output and inflation.

The oil price is perceived to have strong recessionary effects on output from the beginning of the sample until the end of the 1970s, when the effect starts to attenuate (first row, last column in the graph). The perceived effect becomes much

unidentified parameter, the prior distribution will not be updated and its posterior will simply reflect the prior. System estimation, however, is still possible and the remaining parameters can still be identified. 
smaller and very close to zero starting from around 1986 (which is a period of falling oil prices). ${ }^{15}$ The oil price matters again somewhat more after 2000. The perceived effect of the real oil price on inflation has also fallen over time (third row, last column in the graph). The estimated coefficient $\phi_{t}^{\pi, o p}$ is above 0.4 in the early part of the sample, but it is revised downward to around 0.2 after 1985, to 0.1 after 2000 , and very close to 0 at the end of the sample.

Turning to the evolution of other beliefs' coefficients, it is worth noticing the changing perceived sensitivity of output to interest rates (coeff. $\phi_{t}^{y, i}$ ), the increased perceived persistence in the inflation process and in policy choices $\left(\phi_{t}^{\pi, \pi}\right.$ and $\left.\phi_{t}^{i, i}\right)$, and the drop in the anticipated monetary policy response to oil prices after 2000 $\left(\phi_{t}^{i, o p}\right)$.

Through these evolving effects on expectations over time, the overall impact of the oil price on the macroeconomy can considerably vary over the sample. Figure 3 , in fact, illustrates the impulse responses of output and inflation to a positive onestandard-deviation real oil price shock at different points in the sample (the impulse response functions in the model are time-varying as a result of learning dynamics). Oil price shocks had a stronger recessionary effect in the 1970s (the figure shows the impulse response with the beliefs starting at the level they were in 1975:I). In this period, in fact, oil price increases led agents to anticipate a contraction in economic activity and these pessimistic beliefs acted to reinforce the adverse impact of the oil shock. The effect is much more attenuated in 1986:I, since agents had already revised their beliefs about the consequences of oil price changes, as seen in Figure 2. The response becomes again more pronounced at the end of the sample, but still far from its negative peak in the 1970s. A similar situation is apparent for inflation: with the beliefs as in 1979:I, which implied important influences of oil prices on the inflation rate, the impulse response to oil price shocks is substantially larger than the corresponding response in 2008:I. The latter, in fact, is very close to zero as inflation expectations have become rather insulated from oil price fluctuations. The

\footnotetext{
${ }^{15}$ The model with learning seems hence able to account for the muted effect of oil price declines after 1986, without assuming asymmetric effects in the oil price-output relationship.
} 
smaller pass-through of oil prices on inflation obtained in this paper is consistent with the findings obtained using non-structural models by Hooker (2002) and De Gregorio et al. (2007).

Since the influence on expectations has faded, the role of oil prices has become less central. Figure 4 shows the outcome of the forecast error variance decomposition (also time-varying in the model). In 1975 (and generally in most of the 1970s), oil price shocks account for about $20 \%$ of output fluctuations. This percentage falls to slightly more than $5 \%$ in the middle-1980s, and it remains around $15 \%$ in the long-run at the end of the sample. Oil price shocks used to account for about $10 \%$ of the variance in inflation in the 1970s, but they explain less than $5 \%$ in 2008 .

Therefore, the model, by allowing for learning, can successfully rationalize the observed reduced effect of oil prices on macroeconomic variables.

4.3. The Interaction between Oil Price Shocks and Monetary Policy. Several papers have investigated to what extent the recessionary consequences of oil price shocks are in reality due to the contractionary monetary policies that react to the shock with an increase in interest rates (e.g., Bernanke et al., 1997, Leduc and Sill, 2004). I can assess the relative importance of monetary policy responses in amplifying oil price shocks in the context of the structural model. Monetary policy can matter through two channels: through the actual monetary policy reaction to the real oil price variable (coefficient $\chi_{o p, t}$ ), but also through the effect that oil prices have on private agents' expectations about future monetary policies (through the belief coefficient $\phi_{t}^{i, o p}$ ).

I compute the impulse responses under the case in which monetary policy is allowed to respond to oil prices (as estimated in the previous section) and under the alternative case in which actual and expected monetary policy reactions are shut down, i.e., the oil price doesn't enter the Taylor rule and, moreover, agents recognize that oil prices have no effect on future monetary policy decisions (that is, both $\chi_{o p, t}=0$ and $\phi_{t}^{i, o p}=0$ at all $t^{\prime}$ 's). 
Figure 5 shows the implied impulse responses around 1975 and 2008. The actual and perceived monetary policy responses act to amplify the recessionary effects of the original oil price shock (the response of output would, in fact, be smaller had monetary policy not responded). Contractionary monetary policies, however, are very far from explaining all the recessionary effect, which seems still due for the major part to the oil price shock. The additional effect through monetary policy, in fact, contributes for about $20 \%$ of the total cumulative impulse response to the oil price shock (obtained by summing the impulse response over the first 24 periods).

4.4. Robustness. To check the robustness of the empirical results, the model has been re-estimated under different assumptions. First, it can be assumed that monetary policy responds to forecasts of future inflation rather than to current inflation, by modifying the Taylor rule (2.8). ${ }^{16}$ Second, it may be argued that the model may not be able to fully capture the persistence of inflation: therefore, I re-estimate the model under the assumption of inflation indexation in price setting, so that a lagged inflation term also enters the Phillips curve (2.7). As shown in Table 2, the estimates are largely unchanged. Moreover, the estimated degree of indexation (obtained under a Uniform[0,1] prior), denoted by $0 \leq \iota \leq 1$, is small $(\iota=0.102)$, which confirms, as in Milani (2007), that learning can successfully capture the persistence in the model. It is also possible that the results depend on the assumed initial values for the learning process. Therefore, I repeat the estimation under two alternatives: i) the initial beliefs for all the autoregressive coefficients in (2.10) are equal to 0.9 , while for all the other coefficients are equal to 0; ii) all initial beliefs are fixed at 0 . The posterior estimates remain similar, and the evolution of beliefs is also comparable. Taking the beliefs about $\phi_{t}^{\pi, \pi}$ (the AR coefficient in the inflation equation) as an example, in fact, even when initial values in 1959 as far apart as 0.9 and 0 are chosen, the results indicate that the evolution of beliefs in the two cases already become very similar starting from 1970. The estimates, therefore, do

\footnotetext{
${ }^{16}$ The central bank is now assumed to respond to $\widehat{E}_{t-1} \pi_{t+1}$. This can be interpreted in two ways: either the central bank responds to its own internal forecasts, which are formed using the same perceived law of motion used by the private sector, or it responds to observed private-sector expectations.
} 
not seem sensitive to these assumptions and, as a consequence, the implied impulse responses and variance decompositions yield similar conclusions.

\section{Conclusions and Future Directions}

Oil price increases have played a key part in several U.S. recessions and in the stagflation of the 1970s. In recent years, however, their effects on the economy have become milder.

This paper has presented an estimated model that incorporates an effect of oil prices on aggregate demand and inflation, through the role of oil in production and consumption. The model departs from rational expectations by assuming that economic agents adjust their beliefs about the economy and learn over time. Oil prices, therefore, have an additional effect, which operates through their impact on the formation of expectations about future output, inflation, and monetary policies. Since expectations have a large influence on macroeconomic outcomes, the effects of an oil price shock can be substantially amplified if it triggers sizeable revisions in expectations.

The inferred learning process indicates that, during the 1970s, economic agents perceived increases in the price of oil to have large effects on output and inflation. Subsequent data, however, led agents to revise their beliefs by learning that oil prices had a much smaller effect on output starting from the mid-1980s. The perceived impact of oil prices on inflation has also fallen over time: agents' beliefs, therefore, indicate well-anchored inflation expectations and the perception of a highly credible monetary policy.

Through the estimated time variation in the effects that oil prices have on private expectations, the model can account for the changing relationship between oil prices and the macroeconomy that has been observed in practice. As the impulse responses show, the model can account for the large response of output and inflation to oil price shocks in the 1970s and for the smaller responses after the mid-1980s.

Oil prices shocks have been modeled as predetermined. A priority for future research consists of extending the model to treat oil prices as endogenous and to 
disentangle the role of demand and supply shocks in the oil market (Kilian, 2008). Also, the model may be modified to allow for an asymmetric relationship between oil and macroeconomic variables, for example, considering asymmetric expectations effects, following Liu, Waggoner, and Zha (2008).

\section{REFERENCES}

[1] Adam, K., (2005). "Learning to Forecast and Cyclical Behavior of Output and Inflation", Macroeconomic Dynamics, Vol. 9(1), 1-27.

[2] An, S., and F. Schorfheide, (2007). "Bayesian Analysis of DSGE Models", Econometric Reviews, Vol. 26, Iss. 2-4, 113-172.

[3] Altig, D., Christiano, L., Eichenbaum, M., and J. Lindé, (2005). "Firm-Specific Capital, Nominal Rigidities, and the Business Cycle", NBER Working Paper 11034.

[4] Atkeson, A., and P.J. Kehoe, (1999). "Models of Energy Use: Putty-Putty versus PuttyClay", American Economic Review, vol. 89(4),pp. 1028-43.

[5] Bernanke, B., Gertler, M., and M. Watson, (1997). "Systematic Monetary Policy and the Effects of Oil Shocks," Brookings Papers on Economic Activity, 91-157.

[6] Bils, M., and P. Klenow, (2004). "Some Evidence on the Importance of Sticky Prices", Journal of Political Economy, 112, 947-985.

[7] Blanchard, O.J., and J. Galí, (2007). "The Macroeconomic Effects of Oil Price Shocks: Why are the 2000s so Different from the 1970s?", NBER Working Paper No. 13368.

[8] Bruno, M., and J. Sachs, (1985). Economics of Worldwide Stagflation, Harvard University Press: Cambridge Massachusetts.

[9] Clarida, R., J. Galí, and M. Gertler, (2000). "Monetary Policy Rules And Macroeconomic Stability: Evidence And Some Theory," The Quarterly Journal of Economics, vol. 115(1), pages $147-180$.

[10] De Gregorio, J., Landerretche, O., and C. Neilson, (2007). "Another Passthrough Bites the Dust? Oil Prices and Inflation," Economia, Vol. 7(2), pp. 155-196.

[11] Evans, G. W., and S. Honkapohja (2001). Learning and Expectations in Economics. Princeton, Princeton University Press.

[12] Evans, G.W., and S. Honkapohja, (2008). "Expectations, Learning and Monetary Policy: An Overview of Recent Research," CEPR Discussion Paper No. 6640.

[13] Fernandez-Villaverde, J., and J.F. Rubio-Ramírez, (2004). "Comparing Dynamic Equilibrium Economies to Data", Journal of Econometrics, 123, pp 153-187.

[14] Finn, M., (2000). "Perfect Competition and the Effects of Energy Price Increases on Economic Activity", Journal of Money, Credit, and Banking, 32, 400-416.

[15] Fukac, M., and A. Pagan, (2006). "Limited Information Estimation and Evaluation of DSGE Models", NCER WP \# 6 .

[16] Giannoni, M.P., and M. Woodford, (2005). "Optimal Inflation Targeting Rules", in: B.S. Bernanke and M. Woodford, eds., Inflation Targeting, University of Chicago Press.

[17] Hamilton, J. (1983). "Oil and the Macroeconomy since World War II," Journal of Political Economy, 228-248.

[18] Hamilton, J. (1996). "This is What Happened to the Oil Price Macro- economy Relationship," Journal of Monetary Economics, vol. 38(2), 215-220.

[19] Herrera, A.M., and E. Pesavento, (2009). "Oil Price Shocks, Systematic Monetary Policy, and the Great Moderation,", Macroeconomic Dynamics, vol. 13(01), pages 107-137.

[20] Honkapohja, S., Mitra, K., and G. Evans, (2003). "Notes on Agents' Behavioral Rules Under Adaptive Learning and Recent Studies of Monetary Policy", unpublished manuscript.

[21] Hooker, M.A., (1996). "What Happened to the Oil Price Macroeconomy Relationship?," Journal of Monetary Economics, 38, 195-213.

[22] Hooker, M.A., (2002). "Are Oil Shocks Inflationary? Asymmetric and Nonlinear Specifications versus Changes in Regime," Journal of Money, Credit and Banking, vol. 34, no. 2, $540-561$.

[23] Kilian, L., (2008). "Not All Oil Price Shocks Are Alike: Disentangling Demand and Supply Shocks in the Crude Oil Market,", forthcoming, American Economic Review. 
[24] Kilian, L., (2009). "The Economic Effects of Energy Price Shocks", Journal of Economic Literature, 46(4), 871-909.

[25] Kyrtsou, C., (2008). "Nonlinear Features of Commodity Prices Comovements," in Essays in Honor of Prof. Walter Labys, Wiley and Sons.

[26] Kyrtsou, C., and W. Labys, (2006). "Evidence for Chaotic Dependence between US Inflation and Commodity Prices," Journal of Macroeconomics, vol. 28, 1, 256-266.

[27] Leduc, S., and K. Sill, (2004). "A Quantitative Analysis of Oil-Price Shocks, Systematic Monetary Policy, and Economic Downturns," Journal of Monetary Economics, vol. 51(4), pages 781-808.

[28] Liu, Z., D. Waggoner, and T. Zha, (2008). "Asymmetric Expectation Effects of Regime Shifts in Monetary Policy", Review of Economic Dynamics, forthcoming.

[29] Lubik, T., and F. Schorfheide, (2004). "Testing for Indeterminacy: an Application to U.S. Monetary Policy", American Economic Review, 94(1), pp. 190-217.

[30] Milani, F., (2006). "A Bayesian DSGE Model with Infinite-Horizon Learning: Do "Mechanical" Sources of Persistence Become Superfluous?," International Journal of Central Banking, vol. 2(3), 87-106.

[31] Milani, F., (2007). "Expectations, Learning and Macroeconomic Persistence", Journal of Monetary Economics, Vol. 54, Iss. 7, Pages 2065-2082.

[32] Milani, F., (2008a). "Learning, Monetary Policy Rules, and Macroeconomic Stability", Journal of Economic Dynamics and Control, vol. 32(10), pages 3148-3165.

[33] Milani, F., (2008b). "Learning about the Interdependence between the Macroeconomy and the Stock Market", mimeo, UC Irvine.

[34] Nakamura, E., and J. Steinsson, (2008). "Five Facts about Prices: A Reevaluation of Menu Cost Models," The Quarterly Journal of Economics, vol. 123(4), pages 1415-1464.

[35] Nakov, A., and A. Pescatori, (2008). "Oil and the Great Moderation", Economic Journal, forthcoming.

[36] Orphanides, A., and J. Williams, (2005). "The Decline of Activist Monetary Policy: Natural Rate Misperceptions, Learning, and Expectations", Journal of Economic Dynamics and Control, 29(11), 1927-1950.

[37] Poirier, D. (1998), "Revising Beliefs in Nonidentified Models," Econometric Theory, 14(4), 483509.

[38] Rabanal, P., and J.F. Rubio-Ramírez, (2005), "Comparing New Keynesian Models of the Business Cycle: A Bayesian Approach", Journal of Monetary Economics, Vol. 52, Iss. 6 , 1151-1166.

[39] Sargent, T.J., (1993). Bounded Rationality in Macroeconomics. Oxford University Press.

[40] Sargent, T.J., (1999). The Conquest of American Inflation, Princeton University Press.

[41] Sims, C.A., and T. Zha, (2006). "Were There Regime Switches in US Monetary Policy?", American Economic Review, Vol. 96, No. 1, pp. 54-81.

[42] Smets, F., and R. Wouters, (2007). "Shocks and Frictions in US Business Cycles: A Bayesian DSGE Approach," American Economic Review, vol. 97(3), pages 586-606.

[43] Wei, C., (2003). "Energy, the Stock Market, and the Putty-Clay Investment Model," American Economic Review, vol. 93(1), pages 311-323.

[44] Woodford, M., (2003). Interest and Prices: Foundations of a Theory of Monetary Policy. Princeton: Princeton University Press. 


\section{Appendix A. Metropolis-Hastings Algorithm}

The information about the parameters is summarized by the posterior distribution, obtained by Bayes Theorem

$$
p\left(\Theta \mid Z^{T}\right)=\frac{p\left(Z^{T} \mid \Theta\right) p(\Theta)}{p\left(Z^{T}\right)}
$$

where $p\left(Z^{T} \mid \Theta\right)$ denotes the likelihood function, $p(\Theta)$ the prior for the parameters, and $Z^{T}=\left[z_{1}, \ldots, z_{T}\right]^{\prime}$ collects the data histories.

To generate draws from the posterior distribution $p\left(\Theta \mid Z^{T}\right)$, I use the Metropolis algorithm. The procedure works as follows.

1. Start from an arbitrary value for the parameter vector $\Theta_{0}$. Set $j=1$.

2. Evaluate $p\left(Z^{T} \mid \Theta_{0}\right) p\left(\Theta_{0}\right)$.

3. Generate $\Theta_{j}^{*}=\Theta_{j-1}+\varepsilon$, where $\Theta_{j}^{*}$ is the proposal draw and $\varepsilon \sim N\left(0, c \Sigma_{\varepsilon}\right)$. $c$ is a scale factor that is usually adjusted to keep the acceptance ratio of the $\mathrm{MH}$ algorithm at an optimal rate (25\%-50\%). The acceptance rate in the main estimation is $33 \%$.

4. Generate $u$ from a Uniform $[0,1]$.

5. Set $\left\{\begin{array}{l}\Theta_{j}=\Theta_{j}^{*} \quad \text { if } u \leq \alpha\left(\Theta_{j-1}, \Theta_{j}^{*}\right)=\min \left\{\frac{p\left(Y^{T} \mid \Theta_{j}^{*}\right) p\left(\Theta_{j}^{*}\right)}{p\left(Y^{T} \mid \Theta_{j-1}\right) p\left(\Theta_{j-1}\right)}, 1\right\} \\ \Theta_{j}=\Theta_{j-1} \quad \text { if } u>\alpha\left(\Theta_{j-1}, \Theta_{j}^{*}\right)\end{array}\right.$

6. Repeat for $j+1$ from 2. until $j=D$ ( $D=$ total number of draws). 


\begin{tabular}{|c|c|c|c|c|c|c|c|}
\hline & & \multicolumn{4}{|c|}{ Prior Distribution } & \multicolumn{2}{|c|}{ Posterior Distribution } \\
\hline Description & Parameter & Distr. & Support & Prior Mean & 95\% Prior Interval & Posterior Mean & 95\% HPD Interval \\
\hline IES & $\sigma$ & $\Gamma$ & $\mathbb{R}^{+}$ & 1 & {$[0.27,2.20]$} & 3.098 & {$[1.98,4.59]$} \\
\hline Calvo price stick. & $\theta$ & $B$ & {$[0,1]$} & 0.7 & {$[0.47,0.89]$} & 0.764 & {$[0.61,0.9]$} \\
\hline \multirow[t]{2}{*}{ Real Wage rigid. } & $\gamma_{\text {pre79}}$ & $B$ & {$[0,1]$} & 0.9 & {$[0.74,0.99]$} & 0.89 & {$[0.73,0.98]$} \\
\hline & $\gamma_{\text {post } 79}$ & $B$ & {$[0,1]$} & 0.6 & {$[0.47,0.72]$} & 0.61 & {$[0.49,0.73]$} \\
\hline \multirow[t]{2}{*}{ MP Inertia } & $\rho_{\text {pre } 79}$ & $B$ & {$[0,1]$} & 0.8 & {$[0.46,0.99]$} & 0.915 & {$[0.83,0.97]$} \\
\hline & $\rho_{\text {post } 79}$ & $B$ & {$[0,1]$} & 0.8 & {$[0.46,0.99]$} & 0.925 & {$[0.88,0.97]$} \\
\hline \multirow[t]{2}{*}{ MP Inflation feedback } & $\chi_{\pi, \text { pre } 79}$ & $N$ & $\mathbb{R}$ & 1.5 & {$[1.01,1.99]$} & 1.26 & {$[0.74,1.76]$} \\
\hline & $\chi_{\pi, \text { post } 79}$ & $N$ & $\mathbb{R}$ & 1.5 & {$[1.01,1.99]$} & 1.524 & {$[1.03,1.98]$} \\
\hline \multirow[t]{2}{*}{ MP Output feedback } & $\chi_{y, \text { pre } 79}$ & $N$ & $\mathbb{R}$ & 0.25 & {$[0.01,0.49]$} & 0.27 & {$[0.11,0.48]$} \\
\hline & $\chi_{y, p o s t 79}$ & $N$ & $\mathbb{R}$ & 0.25 & {$[0.01,0.49]$} & 0.22 & {$[0.03,0.43]$} \\
\hline \multirow[t]{2}{*}{ MP Oil Price feedback } & $\chi_{\text {op }, \text { pre } 79}$ & $N$ & $\mathbb{R}$ & 0.25 & {$[0.01,0.49]$} & 0.274 & {$[0.02,0.51]$} \\
\hline & $\chi_{\text {op }, \text { post } 79}$ & $N$ & $\mathbb{R}$ & 0.25 & {$[0.01,0.49]$} & 0.255 & {$[0.03,0.48]$} \\
\hline \multirow[t]{2}{*}{ Std. Demand Shock } & $\sigma_{\zeta, p r e 79}$ & $\Gamma^{-1}$ & $\mathbb{R}^{+}$ & 0.33 & {$[0.11,0.9]$} & 0.879 & {$[0.75,1.04]$} \\
\hline & $\sigma_{\zeta, p o s t 79}$ & $\Gamma^{-1}$ & $\mathbb{R}^{+}$ & 0.33 & {$[0.11,0.9]$} & 0.61 & {$[0.54,0.70]$} \\
\hline \multirow[t]{2}{*}{ Std. Supply Shock } & $\sigma_{u, p r e 79}$ & $\Gamma^{-1}$ & $\mathbb{R}^{+}$ & 0.33 & {$[0.11,0.9]$} & 0.295 & {$[0.25,0.35]$} \\
\hline & $\sigma_{u, p o s t 79}$ & $\Gamma^{-1}$ & $\mathbb{R}^{+}$ & 0.33 & {$[0.11,0.9]$} & 0.235 & {$[0.21,0.27]$} \\
\hline \multirow[t]{2}{*}{ Std. MP Shock } & $\sigma_{\varepsilon, p r e 79}$ & $\Gamma^{-1}$ & $\mathbb{R}^{+}$ & 0.33 & {$[0.11,0.9]$} & 0.224 & {$[0.19,0.26]$} \\
\hline & $\sigma_{\varepsilon, p o s t 79}$ & $\Gamma^{-1}$ & $\mathbb{R}^{+}$ & 0.33 & {$[0.11,0.9]$} & 0.242 & {$[0.21,0.28]$} \\
\hline \multirow[t]{2}{*}{ Std. Oil Price Shock } & $\sigma_{v, \text { pre } 79}$ & $\Gamma^{-1}$ & $\mathbb{R}^{+}$ & 0.33 & {$[0.11,0.9]$} & 0.113 & {$[0.1,0.13]$} \\
\hline & $\sigma_{v, p o s t 79}$ & $\Gamma^{-1}$ & $\mathbb{R}^{+}$ & 0.33 & {$[0.11,0.9]$} & 0.127 & {$[0.11,0.15]$} \\
\hline AR coeff. $\zeta_{t}$ & $\rho_{\zeta}$ & $B$ & {$[0,1]$} & 0.8 & {$[0.46,0.99]$} & 0.657 & {$[0.53,0.8]$} \\
\hline AR coeff. $u_{t}$ & $\rho_{u}$ & $B$ & {$[0,1]$} & 0.8 & {$[0.46,0.99]$} & 0.353 & {$[0.23,0.48]$} \\
\hline AR coeff. $v_{t}$ & $\rho_{v}$ & $B$ & {$[0,1]$} & 0.8 & {$[0.46,0.99]$} & 0.278 & {$[0.15,0.43]$} \\
\hline Sens. OP to output & $\delta_{o p, y}$ & $N$ & $\mathbb{R}$ & 0 & {$[-0.24,0.24]$} & 0.0026 & {$[-0.03,0.04]$} \\
\hline Sens. OP to real rate & $\delta_{o p, r}$ & $N$ & $\mathbb{R}$ & 0 & {$[-0.24,0.24]$} & 0.005 & {$[-0.003,0.014]$} \\
\hline AR coeff. $o p_{t}$ & $\rho_{o p}$ & $B$ & {$[0,1]$} & 0.9 & {$[0.74,0.99]$} & 0.96 & {$[0.91,0.99]$} \\
\hline Initial beliefs $y$ on $o p$ & $-\phi_{t=0}^{y, o p}$ & $\Gamma$ & $\mathbb{R}^{+}$ & 1 & {$[0.12,2.78]$} & $\begin{array}{l}1.01 \\
(0.44)\end{array}$ & {$[0.29,2.13]$} \\
\hline Initial beliefs $\pi$ on $o p$ & $\phi_{t=0}^{\pi, o p}$ & $\Gamma$ & $\mathbb{R}^{+}$ & 1 & {$[0.21,2.4]$} & $\begin{array}{l}0.45 \\
(0.17)\end{array}$ & {$[0.16,0.82]$} \\
\hline Initial beliefs $i$ on $o p$ & $\phi_{t=0}^{i, o p}$ & $\Gamma$ & $\mathbb{R}^{+}$ & 0.25 & {$[0.03,0.7]$} & $\begin{array}{l}0.261 \\
(0.17)\end{array}$ & {$[0.03,0.75]$} \\
\hline
\end{tabular}

Table 1 - Prior and Posterior Distributions.

Note: the table reports prior means and $95 \%$ prior probability intervals, along with posterior mean estimates for each parameter and the corresponding 95\% Highest Posterior Density (HPD) interval (the numbers in parentheses below the mean estimate denote standard deviations across the chain). Coefficient $\phi_{t=0}^{y, o p}$ is thought to enter the model negatively: therefore, I assume a Gamma prior for $-\phi_{t=0}^{y, o p}$ to ensure its negativity. The symbols in the table denote the following prior distribution: $U=$ Uniform, $N=$ Normal, $\Gamma=$ Gamma, $B=$ Beta, $\Gamma^{-1}=$ Inverse Gamma. 


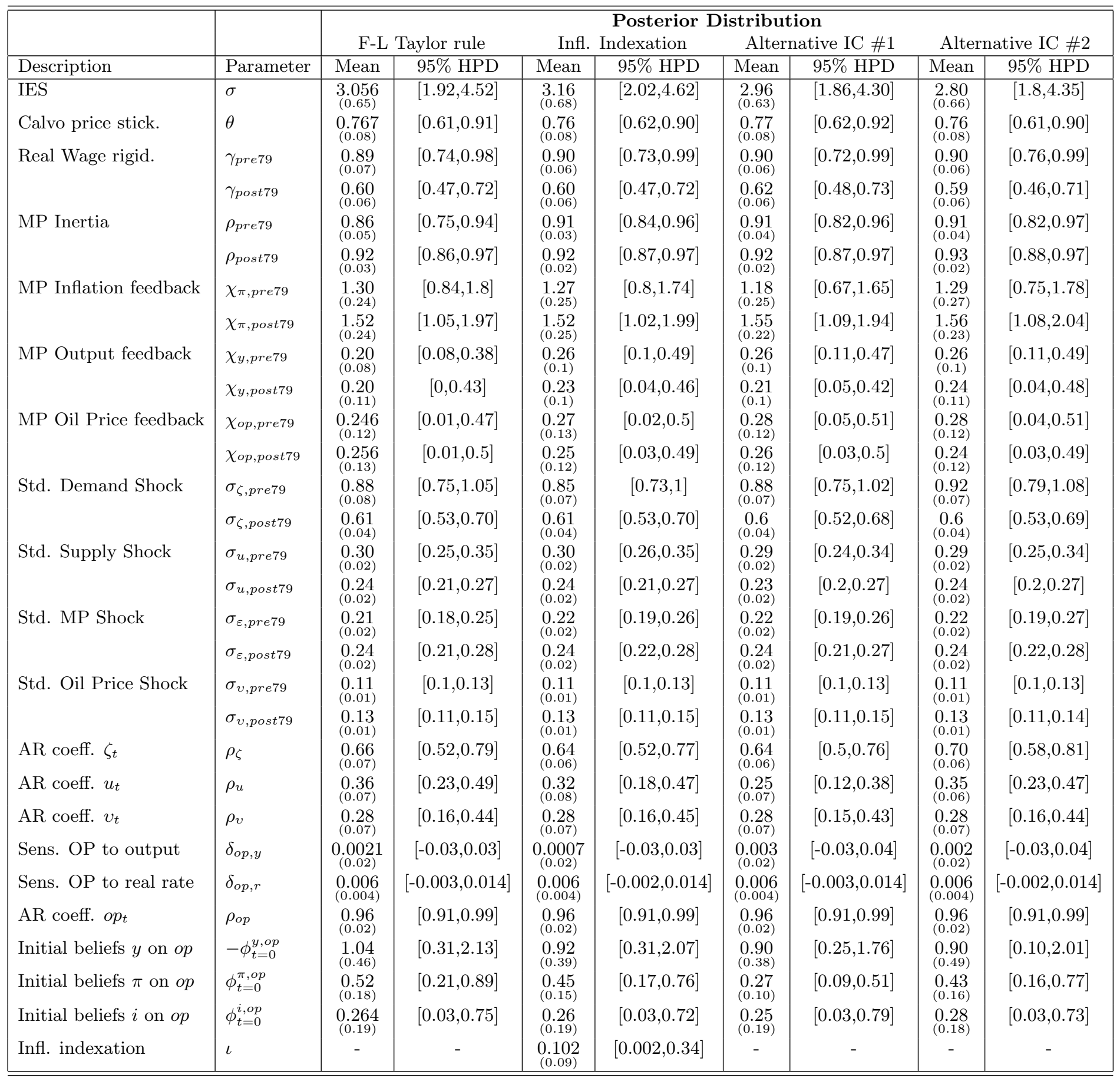

Table 2 - Sensitivity Analysis. Posterior distributions under alternative assumptions: i) forward-looking Taylor rule; ii) inflation indexation; iii) alternative initial conditions for learning algorithm, case 1; iv) alternative initial conditions for learning algorithm, case 2. 

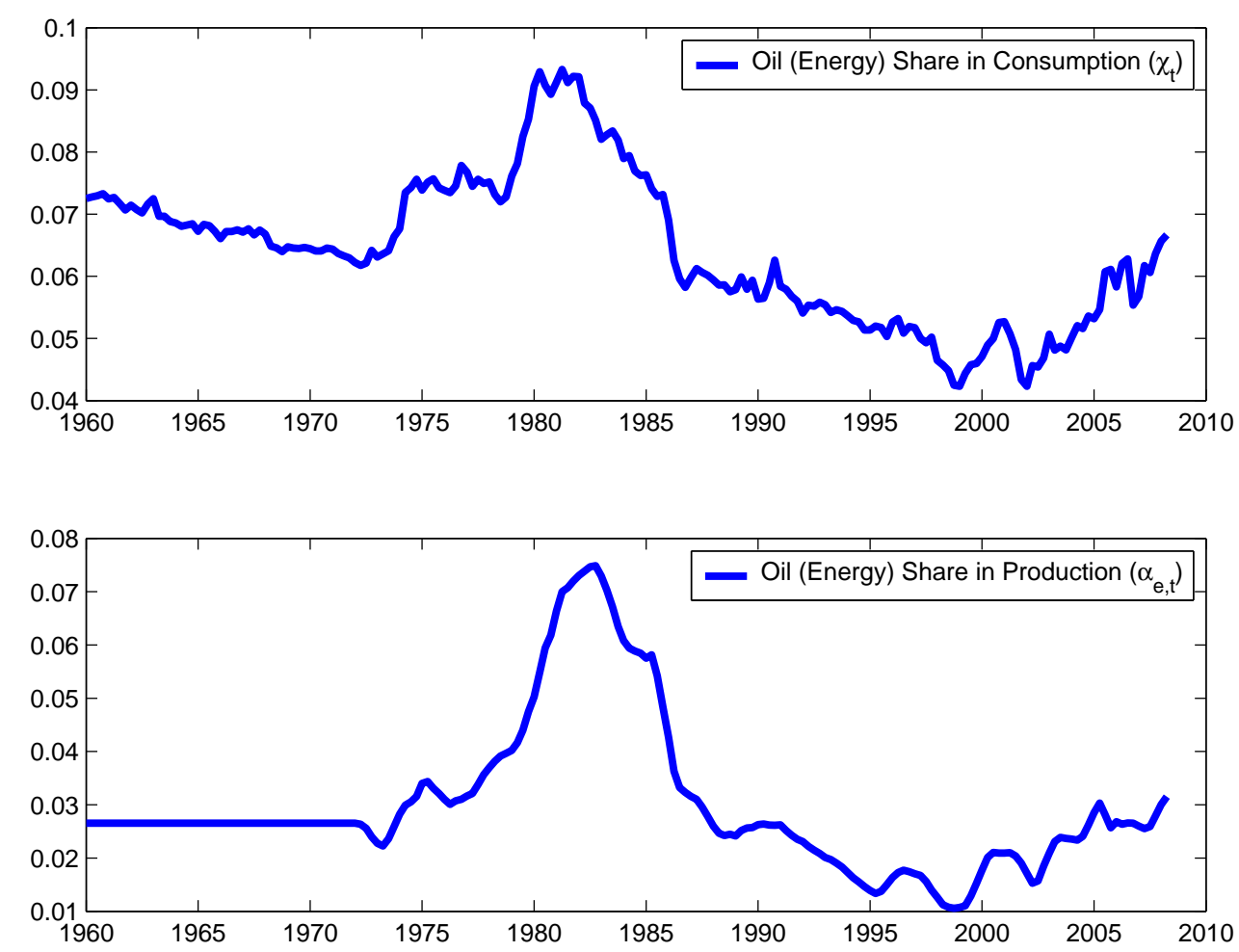

Figure 1. Oil shares in consumption and production. These shares correspond to time-varying parameters $\chi_{t}$ and $\alpha_{e, t}$ in the model. 

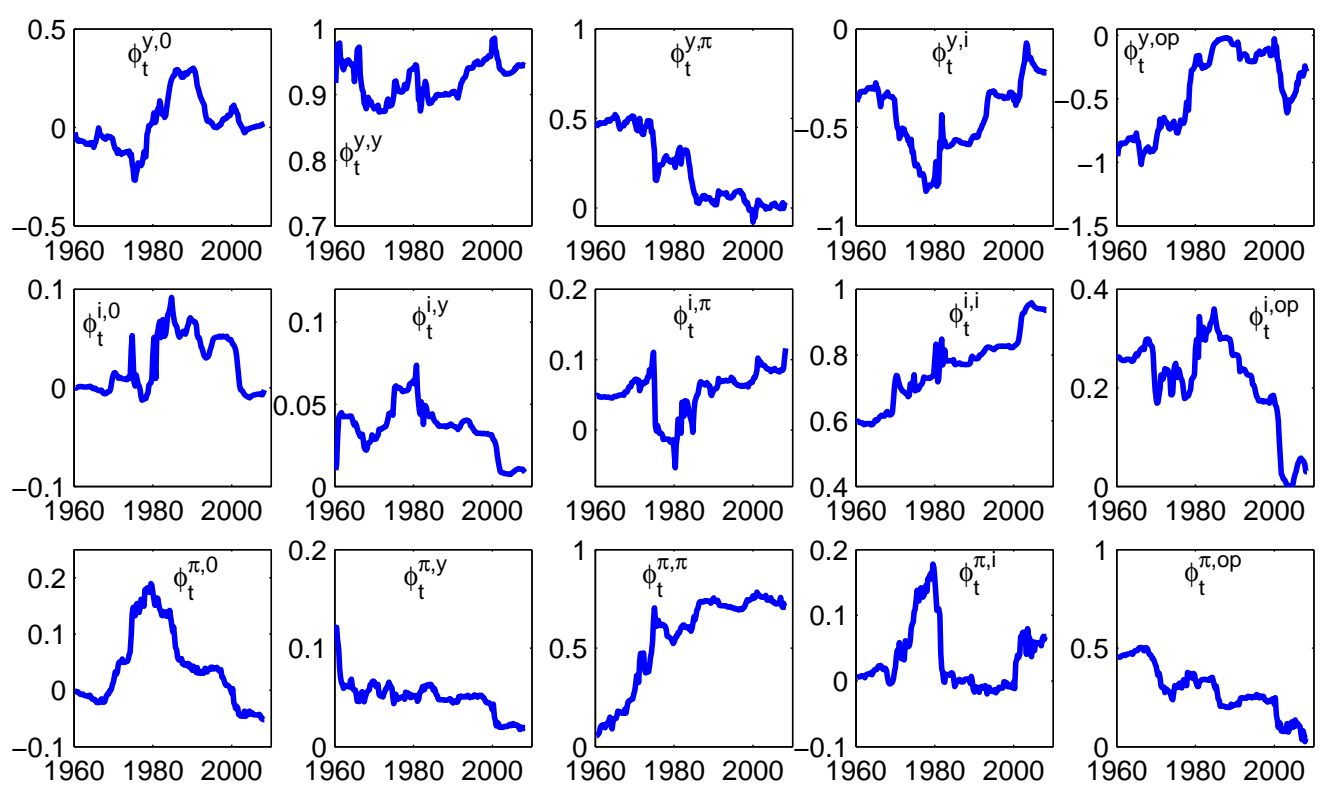

196019802000
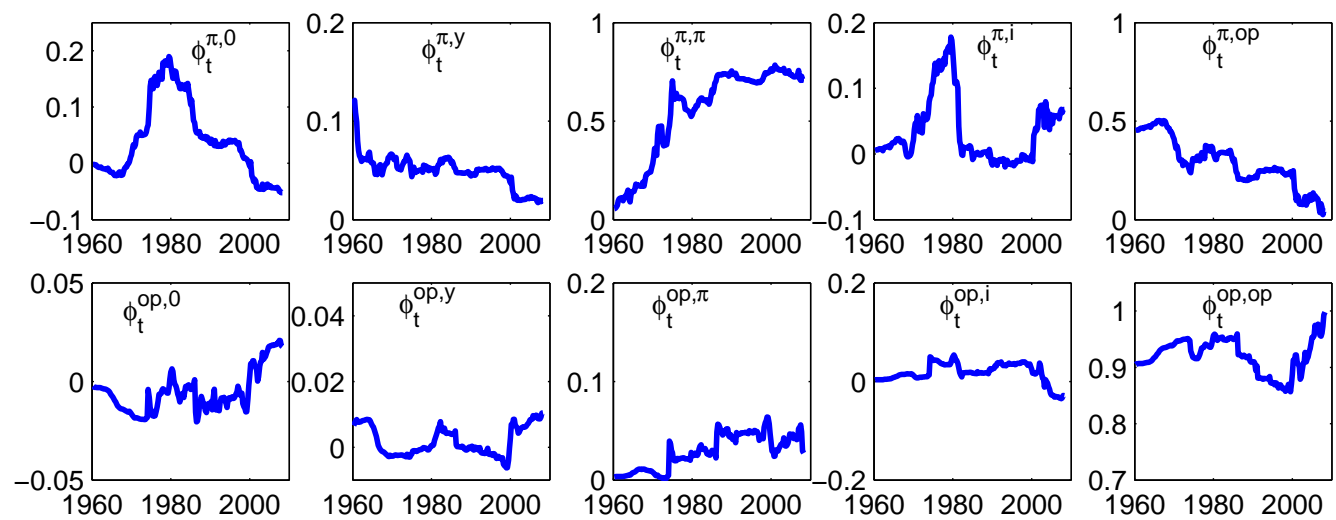

FIgURE 2. Evolving agents' beliefs: full set of beliefs. Note: The beliefs refer to the PLM given by (2.10). 

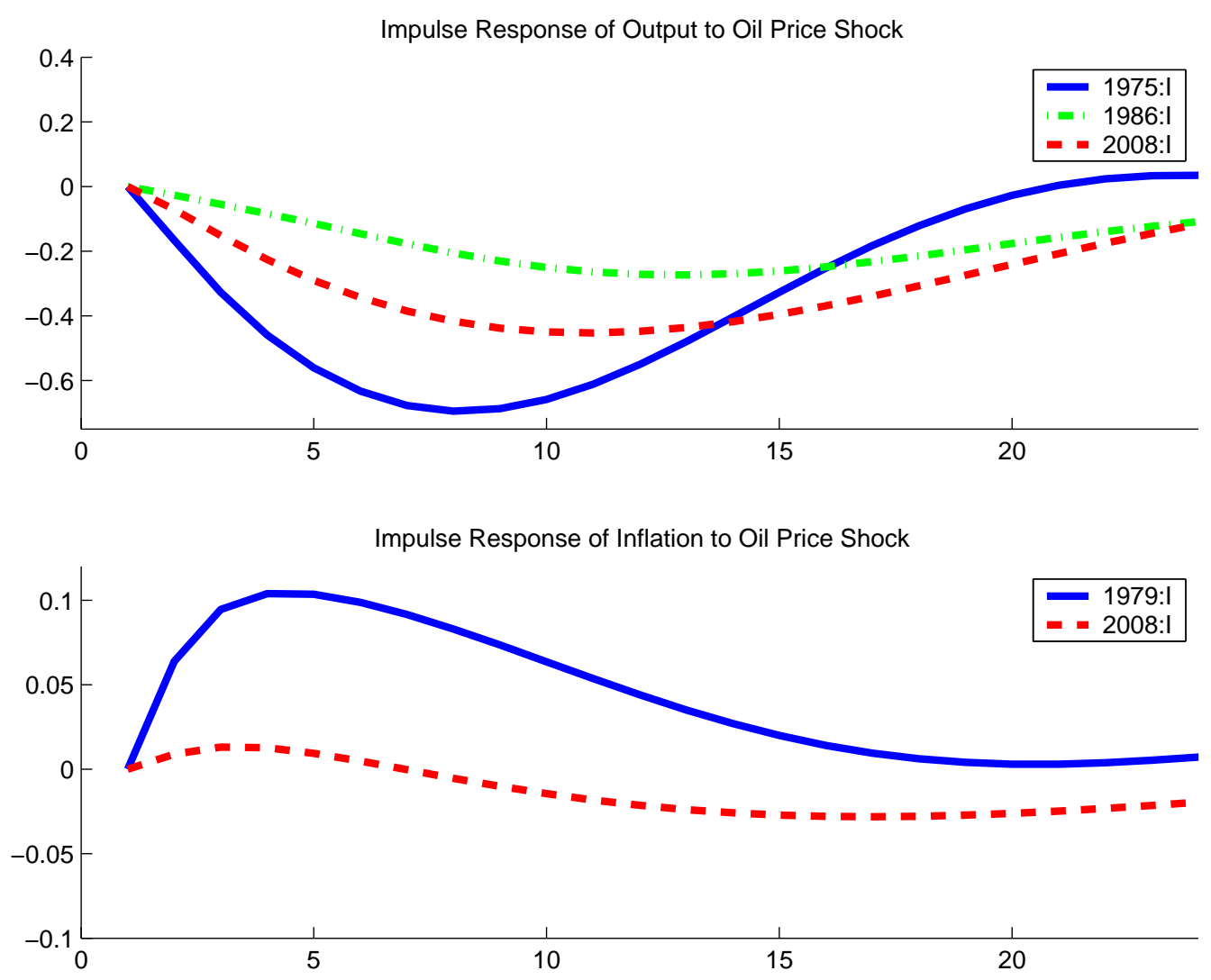

FiguRE 3. Impulse Response Functions of Output and Inflation to a positive one-standard-deviation Real Oil Price Shock at different points in the sample. 

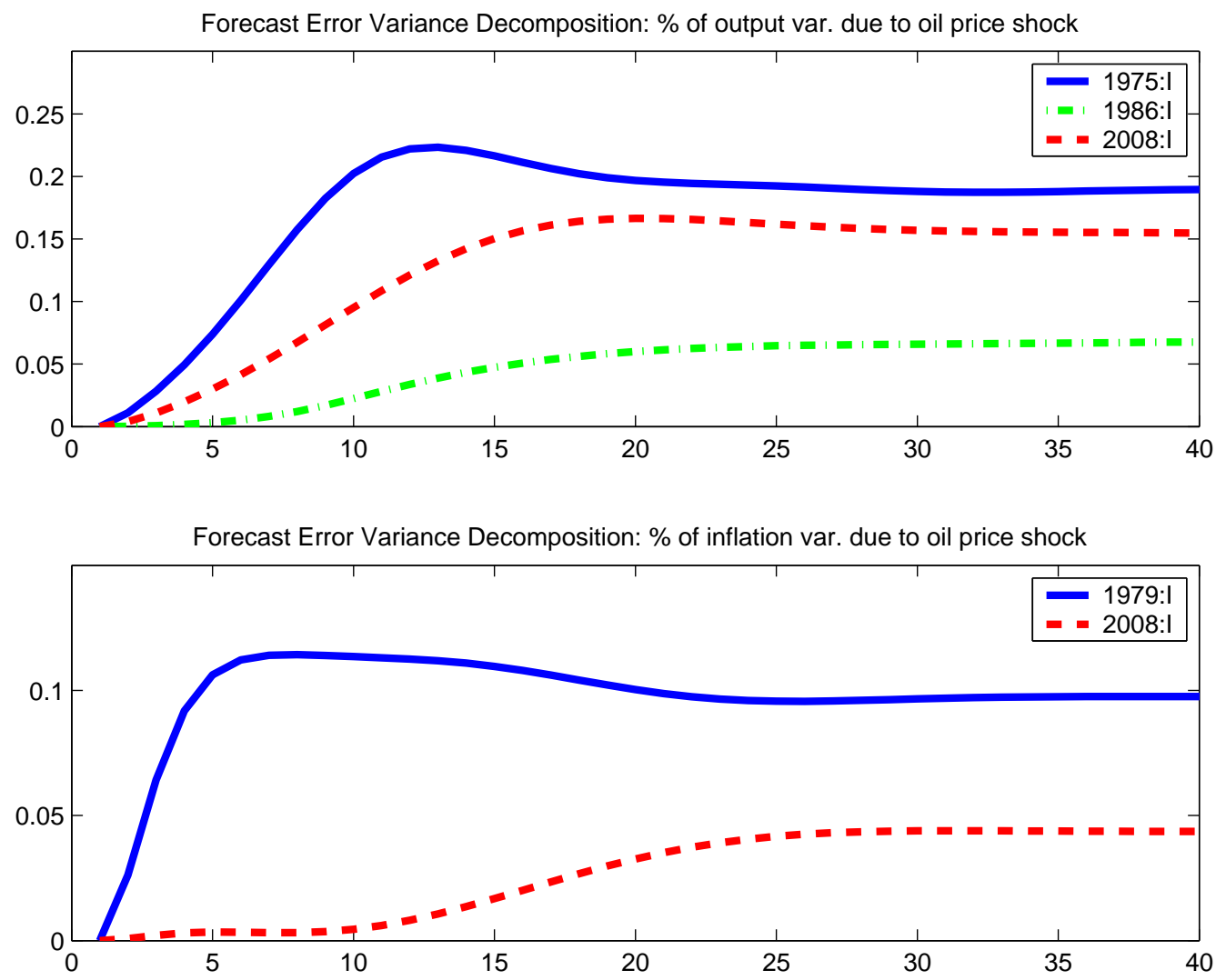

FIgURE 4. Forecast Error Variance Decomposition: percentage of variance of output and inflation due to Real Oil Price Shock over the sample and at different horizons (up to $h=40$ ). 

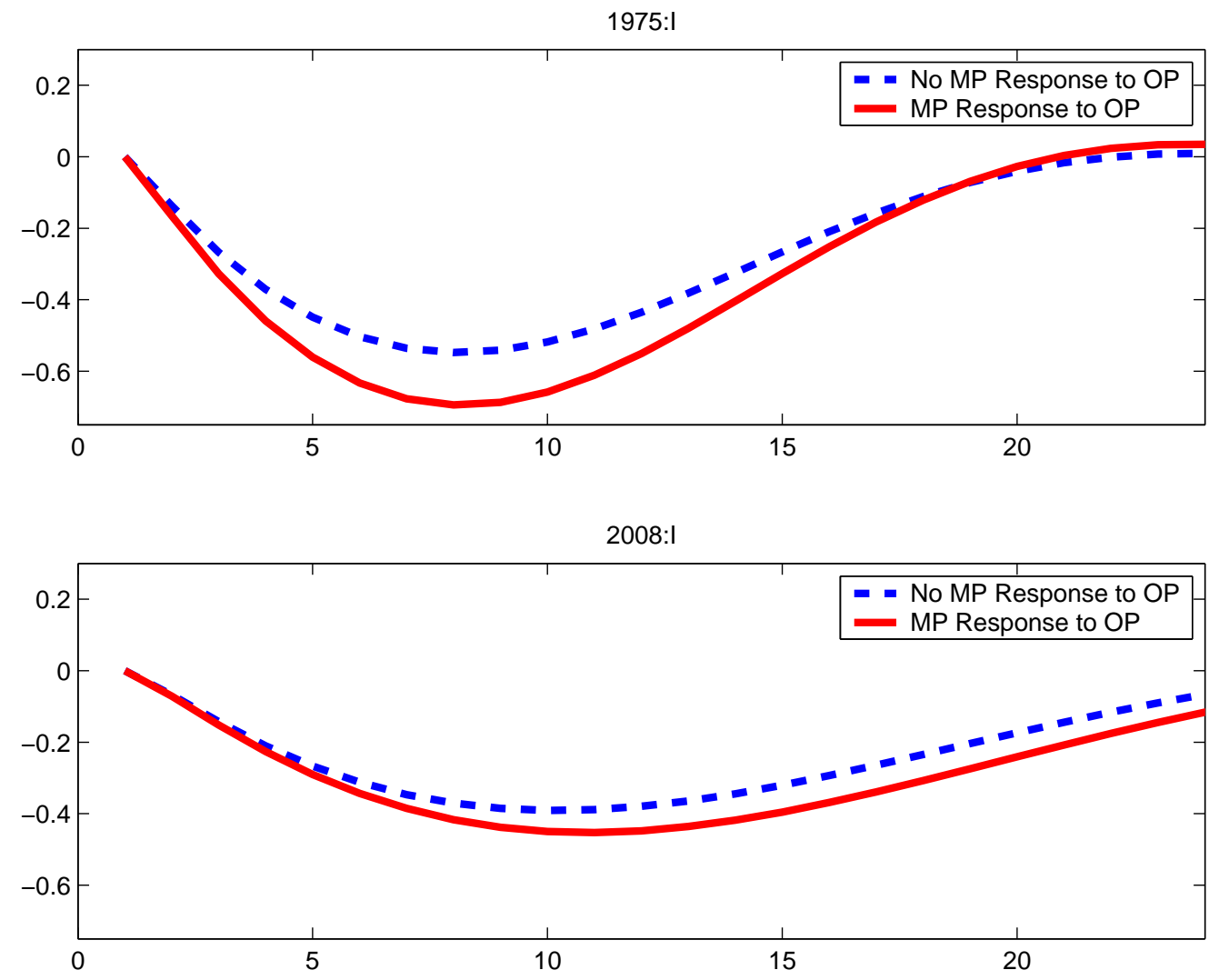

FiguRE 5. Impulse Response Functions of Output to a positive one-standard-deviation Real Oil Price Shock: the figure illustrates the cases with (solid line) or without (dashed line) actual and perceived Monetary Policy Response to Oil Prices. 